\title{
EVALUASI TATA KELOLA DAN AUDIT SISTEM INFORMASI RUMAH SAKIT GANESHA DENGAN MENGGUNAKAN KERANGKA KERJA COBIT 5
}

\author{
Dewa Gede Eka Krisna Prandana ${ }^{1}$ \\ A.A. Istri Ita Paramitha ${ }^{2}$ \\ I Gede Juliana Eka Putra ${ }^{3}$
}

\author{
Sekolah Tinggi Manajemen dan Informatika Primakara, Denpasar 1,2,3 \\ email: krisnadewa29@gmail.com
}

\begin{abstract}
Ganesha Hospital has implemented IT using SIMRS Ganesha in collaboration with Vendor CV Nayaka to create the system. But there are still problems in the application of the Ganesha SIMRS. In its application there are still errors in recording the patient's medical records that have an impact on the determination of patient medication as well as inputting patient administration payment data, this problem is included in the EDM4 domain (ensuring resource optimization) and APO7 (managing human resources), BPJS verification issues, namely for BPJS verification. health cost control and the absence of BPJS system integration, this problem is included in the DSS6 domain (managing and controlling business processes) and patient database maintenance has not been done, and if maintenance is not done, then the data in Ganesha Hospital is invalid this problem is included in the domain MEA3 (monitor, evaluate and evaluate conformity with external needs). Because there are still obstacles in the information technology governance system at Ganesha Hospital it is deemed necessary to be studied more deeply by evaluating governance. The method of research carried out based on the COBIT 5 framework uses the EDM4, APO7, DSS6, and MEA3 domains. Furthermore, calculations are performed with the ISO / IEC 15504 capability model. The results of the maturity of IT governance at SIMRS Ganesha are obtained with an average of 2.77 and are at level 3 (Established) with an average gap value of 2.23. To improve IT governance at Ganesh Hospital, it must improve governance in the EDM4, APO7, DSS6, and MEA3 domains according to recommendations.
\end{abstract}

Keywords: $\quad$ IT governance, COBIT 5, ISO / IEC 15504, SIMRS.

\section{PENDAHULUAN}

Peranan teknologi memberikan dampak dan pengaruh yang luar biasa dalam peranannya menyediakan informasi dalam pengambilan keputusan. Investasi teknologi informasi terkadang tidak memperhatikan nilai tambah yang akan diberikan, untuk itu perlu dilakukan kematangan tata kelola teknologi informasi pada layanan TI. Sehingga nantinya memberikan masukan dan rekomendasi guna perbaikan proses layanannya.

Kerangka COBIT merupakan kerangka yang lengkap untuk membantu organisasi melakukan perencanaan, pelaksanaan, monitor dan evaluasi teknologi informasi. Untuk itu dilakukan tahapan penelitian dengan memetakan tujuan bisnis ke dalam tujuan IT yang berkaitan langsung dengan proses layanan 
teknologi Informasi. Maka dari itu untuk menjaga agar teknologi informasi menjadi penambah nilai dalam sebuah perusahaan atau institusi, maka perlu adanya tata kelola teknologi informasi yang baik. Dengan adanya tata kelola TI, semua faktor dan dimensi yang berhubungan dengan penggunaan teknologi informasi menjadi bersinergi dan bisa memberikan nilai tambah yang diharapkan bagi perusahaan atau institusi.

Dalam hal ini banyak Institusi serta lembaga kesehatan yang mulai melakukan Audit sistem informasi agar dapat membenahi sistem yang di anggap kurang menjadi sistem yang baik. Menurut (Elmolya, 2011) audit TI itu sendiri merupakan proses pengumpulan dan evaluasi bukti-bukti untuk menentukan apakah sistem komputer yang digunakan telah dapat melindungi aset milik organisasi, mampu menjaga integritas data, dapat membantu pencapaian tujuan pada organisasi tersebut secara efektif, serta menggunakan sumber daya yang dimiliki secara efisien.

Penerapan TI sendiri telah menyebar hampir ke seluruh aspek kehidupan, salah satunya pada bidang kesehatan. Penerapan TI pada Rumah Sakit telah diterapkan sebagai sarana untuk mengoptimalkan kinerja pegawai agar mempermudah pelayanan dan memberikan kenyamanan bagi pasien. Walaupun penerapan tersebut belum optimal, banyak hal yang telah dilakukan untuk mengoptimalkannya, salah satunya dengan cara melakukan audit TI pada suatu Rumah Sakit. Contohnya pada RS Ganesha telah memanfaatan TI sebagai salah satu faktor pendukung untuk melaksanakan rencana strategis serta telah di kembangkan secara optimal oleh RS Ganesha. RS Ganesha sendiri merupakan rumah sakit umum yang berletak di Kabupaten Gianyar. Dalam pelayanannya RS Ganesha telah menerapkan TI menggunakan SIMRS Ganesha bekerja sama dengan Vendor CV Nayaka untuk membuat system tersebut.

Sistem rumah sakit ini sudah terintegrasi kesetiap bagian di Rumah Sakit Ganesha, baik dalam pelayanan pasien dan pada para pekerja di RS Ganesha. Di RS Ganesha menggunakan jaringan LAN (Local Area Network) atau jaringan lokal sehingga dapat menjamin keamanan data yang dimiliki oleh RS Ganesha. Namun walaupun telah menggunakan sistem yg sudah terintegrasi dengan baik tetapi masih terdapat beberapa kendala di RS Ganesha.

Berdasarkan wawancara yang telah dilakukan bersama staff IT RS Ganesha didapatkan informasi bahwa pada faktor SDM masih ada staff Rumah sakit yang melakukan kesalahan penginputan data pasien di Rumah Sakit Ganesha yaitu kesalahan dalam mendata rekam medis pasien yang berdampak pada penentuan obat pasien serta kesalahan penginputan data pembayaran administrasi pasien, masalah ini termasuk kedalam domain EDM4 (memastikan pengoptimalan sumber daya) dan APO7 (mengatur sumber daya manusia), masalah verifikasi BPJS yaitu untuk pengeklaiman biaya kesehatan serta belum adanya integrasi sistem BPJS, masalah ini termasuk ke dalam domain DSS6 (mengelola dan mengkontrol proses bisnis) serta belum dilakukannya maintenance Database pasien, dan apabila tidak dilakukannya maintenance, maka data pada RS ganesha tidak valid masalah ini termasuk ke dalam domain MEA3 
(monitor, evaluasi, dan penilaian kesesuaian dengan kebutuhan eksternal).

Mencermati kondisi tersebut nampak ada kesenjangan antara yang direncanakan dengan realitas yang terjadi. Sehingga evaluasi tata kelola diperlukan untuk mencari tahu bagaimana pelaksanaan tata kelola, bagaimana tingkat kematangan tata kelola yang telah dilakukan sehingga dapat diusahakan jalan keluar atau solusi yang tepat untuk pengembangan dan peningkatan tata kelola. Tata kelola TI atau IT (Information Technology) Governance merupakan struktur hubungan dan proses untuk mengarahkan dan mengendalikan organisasi untuk mencapai tujuannya dengan menambahkan nilai ketika menyeimbangkan risiko dibandingkan dengan TI dan prosesnya (Utomo dan Mariana, 2011).

Dikarenakan masih terdapat kendala-kendala pada system tata kelola teknologi informasi RS Ganesha dirasa perlu untuk dikaji lebih mendalam dengan melakukan evaluasi tata kelola. Evaluasi tata kelola diperlukan untuk mencari tahu bagaimana pelaksanaan tata kelola, bagaimana tingkat kematangan tata kelola yang telah dilakukan dan masalah-masalah apa yang dihadapi, sehingga dapat dicarikan jalan keluar dan rekomendasi yang tepat untuk peningkatan dan pengembangan. Cara penelitian yang dilakukan berdasarkan kerangka kerja COBIT 5, yang telah dimodifikasi dan disesuaikan dengan kondisi yang ada di tempat penelitian. Modifikasi yang akan dilakukan yaitu mengukur beberapa aktivitas kegiatan dari beberapa domain yang ada pada COBIT 5.

\section{TINJAUAN PUSTAKA}

Tata kelola TI (IT Governance)

Tata kelola TI (ITGovernance) adalah wewenang dan tanggung jawab secara benar dalam menetapkan suatu keputusan untuk mendorongg perilaku penggunaan teknologi informasi pada perusahaan [7]. IT Governance merupakan suatu komitmen, kesadaran, dan proses pengendalian manajemen organisasi terhadap sumber daya TI/sistem informasi yang dibeli dengan harga mahal tersebut, yang mencakup mulai dari sumber daya komputer (software, brainware, database, dan sebagainya) hingga ke teknologi informasi dan jaringan LAN (Local Area Network)/internet.

Banyak framework yang digunakan untuk mengukur tingkat kematangan keselarasan strategi TI dengan strategi bisnis atau organisasi, salah satunya dengan (Control Objective for Information and related Technology) COBIT, karena dinilai memiliki spectrum paling lengkap dan menyeluruh sebagai framework IT audit karena di kembangkan secara berkelanjutan oleh lembaga swadaya professional auditor yang terbesar di hamper seluruh Negara. Dimana di setiap Negara dibangun charter yang dapat mengelola para professional tersebut [1].

\section{COBIT 5}

COBIT versi 5 atau dikenal dengan nama COBIT 5 adalah edisi terbaru dari Framework COBIT ISACA yang menyediakan penjabaran bisnis secara end-to-end dari tata kelola teknologi informasi perusahaan untuk menggambarkan peran utama dari informasi dan teknologi dalam menciptakan nilai perusahaan. COBIT 5 adalah sebuah versi pembaharuan yang menyatukan cara berpikir yang 
mutakhir di dalam teknik-teknik dan tata kelola TI perusahaan. Menyediakan prinsip-prinsip, praktekpraktek, alat-alat analis yang telah diterima secara umum untuk meningkatkan kepercayaan dan nilai sistem-sistem informasi. COBIT 5 dibangun berdasarkan pengembangan dari COBIT 4.1 dengan mengintegrasikan Value IT dan Risk IT dari ISACA, ITIL, dan standar-standar yang relevan dari ISO.

\section{ISO/IEC 15504}

ISO/IEC 15504, atau dikenal juga dengan SPICE (Software Process Improvement and Capability determination) adalah suatu "kerangka kerja untuk penilaian proses" yang dikembangkan bersama oleh ISO (International Organization for Standardization) dan IEC (International Electrotechnical Commission). ISO/IEC 15504 awalnya diturunkan dari standar siklus hidup proses ISO 12207 dan digunakan sebagai dasar pembuatan Capability Maturity Model (CMM) [5]. Tingkat kapabilitas suatu proses pada model ISO/IEC 15504 memiliki nilai dari 0 (incomplete), 1 (performed), 2 (managed), 3 (established), 4 (predictable), hingga 5 (optimizing), menurut referensi [3], kegiatan penilaian membedakan antara penilaian untuk level 1 dengan level yang lebih tinggi. Hal ini dilakukan karena level 1 menentukan apakah suatu proses mencapai tujuannya, dan oleh karena itu sangat penting untuk dicapai, dan juga menjadi pondasi dalam meraih level yang lebih tinggi. Dalam penilaian pada tiap levelnya, hasil akan diklarifikasikan dalam 4 kategori sebagai berikut:
1. N (Not achieved / tidak tercapai), artinya dalam kategori ini tidak ada atau hanya sedikit bukti atas pencapaian atribut proses tersebut. Range nilai yang diraih pada kategori ini berkisar 0-15\%.

2. P (Partially achieved / tercapai sebagian), pada kategori ini terdapat beberapa bukti mengenai pendekatan, dan beberapa pencapaian atribut atas proses tersebut. Range nilai yang diraih pada kategori ini berkisar $15-50 \%$.

3. L (Largely achieved / secara garis besar tercapai), dalam kategori ini terdapat bukti atas pendekatan sistematis, dan pencapaian signifikan atas proses tersebut, meski mungkin masih ada kelemahan yang tidak signifikan. Range nilai yang diraih pada kategori ini berkisar 50-85\%.

F (Fully achieved / tercapai penuh), jika terdapat bukti atas pendekatan sistematis dan lengkap, dan pencapaian penuh atas atribut diklarifikasikan dalam kategori ini. Tidak ada kelemahan terkait atribut proses tersebut. Range nilai yang diraih pada kategori ini berkisar antara $85-100 \%$.

\section{METODE PENELITIAN}

Penelitian ini adalah penelitian kualitatif. Penelitian kualitatif adalah suatu metode penelitian yang berlandaskan pada filsafat positivisme, yang digunakan untuk meneliti pada kondisi objek yang alamiah, (sebagai lawannya adalah eksperimen) yang dimana peneliti merupakan sebagai instrumen kunci, dari pengambilan sampel sumber data yang dilakukan dengan cara purposive dan snowball, teknik pengumpulan trianggulasi, analisa data yang bersifat induktif atau kualitatif, dan hasil 
penelitian kualitatif lebih menekan pada makna dari generalisasi [6].

Jenis pendekatan yang digunakan adalah pendekatan studi kasus. Penelitian studi kasus berorientasi untuk memahami, menggali, dan menafsirkan arti dan peristiwa-peristiwa, dan hubungan dengan orang-orang yang biasa dalam kasus tertentu. Ini biasa disebut dengan penelitian kualitatif dengan menggunakan pengamatan terhadap fenomena-fenomena atau gejalagejala sosial yang alamiah yang berdasarkan kenyataan lapangan (empiris) [6].

Dalam penelitian ini kasus yang diteliti adalah evaluasi tata kelola TI khususnya dalam penerapan layanan sistem informasi di RS Ganesh. Evaluasi layanan sistem informasi di RS Ganesh menggunakan framework COBIT 5 pada domain EDM4 (memastikan pengoptimalan sumber daya), APO7 (mengatur sumber daya manusia), DSS6 (mengelola dan mengkontrol proses bisnis), dan domain MEA3 (monitor, evaluasi, dan penilaian kesesuaian dengan kebutuhan eksternal).

Selanjutnya dilakukan
penilaian berdasarkan
kapabilitas ISO/IEC 15504 untuk mengetahui tingkat kematangan tata kelola TI. Hasil penilaian digunakan untuk merumuskan rekomendasi yang mungkin diberikan sebagai perbaikan tata kelola TI dalam sistem informasi di RS Ganesha.

Pengumpulan data dilakukan dengan teknik survei, kuesioner, wawancara, dan studi dokumentasi. Untuk mendapat data yang akurat dilakukan teknik triangulasi metode pengumpulan data, yaitu pengumpulan informasi yang sama dengan metode yang berbeda, dan pengumpulan informasi dengan metode yang sama pada informan atau sumber data yang berbeda.

Teknik analisis data dilakukan dengan 3 cara sebelum merumuskan rekomendasi perbaikan, analisis kematangan saat ini, diperoleh dari hasil pengumpulan data yang dilakukan. Analisis kematangan yang diharapkan diperoleh dengan teknik wawancara kepada pimpinan organisasi atau manajer TI (CIO). Selanjutnya analisis kesenjangan diperoleh dengan membandingkan level antara tingkat kematangan yang diharapkan dengan tingkat kematangan saat ini. Hasil perbandingan ini disebut jarak (gap) yang harus diperkecil organisasi dalam kurun waktu tertentu dengan cara melaksanakan rekomendasi perbaikan yang diberikan oleh peneliti.

\section{HASIL DAN PEMBAHASAN Identifikasi Proses Domain COBIT 5}

Dalam tahap ini, peneliti menentukan proses domain, sub domain dan aktivitas proses pada COBIT 5 terkait dengan masalah yang ada pada RS Ganesh. Domain, sub domain dan aktivitas proses COBIT 5 pada RS Ganesha dapat dilihat pada tabel berikut: 
Journal of Applied Management and Accounting Science (JAMAS)

(Dewa Gede Eka Krisna Prandana, A.A. Istri Ita Paramitha, I Gede Juliana Eka Putra, 65 - 75) Vol 1, No 1, Desember 2019

\begin{tabular}{lll}
\hline & \multicolumn{1}{c}{ Tabel 4.1 Tabel Domain, } \\
& \multicolumn{2}{c}{ Sub domain dan aktivitas proses COBIT 5 } \\
\hline Proses & $\begin{array}{c}\text { Aktivitas } \\
\text { Proses }\end{array}$ & Deskripsi Aktivitas \\
\hline \multirow{2}{*}{ EDM 4 } & EDM04.01 & Mengevaluasi Sumber Daya Manajemen \\
& EDM04.02 & Mengarahkan Sumber Daya Manajemen \\
& EDM04.03 & Memantau Sumber Daya Manajemen \\
& APO07.01 & Memelihara kecukupan dan Susunan Kepegawaian yang baik \\
& APO07.02 & Mengidentifikasi Kunci IT Personil \\
APO 7 & APO07.03 & Memelihara kemampuan dan kompetensi dari personil \\
& APO07.04 & Mengevaluasi kinerja kerja pegawai \\
& APO07.05 & Rencana dan jalan penggunaan IT dan bisnis pada sumber daya manusia . \\
& APO07.06 & Mengatur Staff Kontrak \\
& DSS06.01 & Sejajarkan kegiatan pengendalian tertanam dalam proses bisnis dengan \\
& tujuan perusahaan. \\
DSS06.02 & Kontrol pengolahan informasi. \\
DSS 6 & DSS06.03 & Kelola peran, tanggung jawab, hak akses dan tingkat kewenangan. \\
& DSS06.04 & Kelola kesalahan dan pengecualian. \\
& DSS06.05 & Memastikan ketertelusuran peristiwa informasi dan akuntabilitas. \\
& DSS06.06 & Aset informasi aman. \\
& MEA03.01 & Mengidentifikasi persyaratan kepatuhan eksternal. \\
& MEA03.02 & Mengoptimalkan \\
MEA 3 & menanggapi kebutuhan eksternal. \\
& MEA03.03 & Konfirmasi kepatuhan eksternal. \\
& MEA03.04 & Memperoleh keyakinan kepatuhan eksternal. \\
\hline & &
\end{tabular}

\section{Analisis Tingkat Kematangan}

Pada tahap ini penulis melakukan penilaian terhadap masingmasing aktivitas berdasarkan hasil kuesioner seluruh responden. Setelah masing-masing aktivitas memperoleh nilai selanjutnya penulis menggabungkan seluruh nilai aktivitas dan mencari rata-rata untuk mendapatkan tingkat kematangan saat ini (as-is) pada tiap domain. Penilaian tingkat kematangan setiap proses TI mengacu pada model ISO/IEC 15504 dan dihitung dengan rumus:

$$
\text { Maturity }=\frac{\text { Total nilai }}{\text { Jumlah soal }}
$$

\section{Rata-rata Hasil Analisis Kuesioner} Hasil dari rata-rata seluruh domain proses lalu dibulatkan untuk menentukan level kematangan yang sesuai dengan penilaian ISO/IEC 15504 tertera pada tabel berikut

Tabel 4.3 Tabel Rata-rata Analisis Tingkat Kematangan Saat ini

\begin{tabular}{|c|c|c|c|c|}
\hline $\begin{array}{l}\text { Domain } \\
\text { Proses }\end{array}$ & Deskripsi Proses & $\begin{array}{l}\text { Rat } \\
\text { a- } \\
\text { rata }\end{array}$ & Level & Kondisi \\
\hline EDM 4 & $\begin{array}{l}\text { Memastikan } \\
\text { Pengoptimalan Sumber } \\
\text { Daya }\end{array}$ & 2.78 & 3 & Established \\
\hline APO 7 & $\begin{array}{l}\text { Mengatur Sumber Daya } \\
\text { Manusia } \\
\text { Mengelola dan }\end{array}$ & 2.94 & 3 & Established \\
\hline DSS 6 & $\begin{array}{l}\text { Mengkontrol Proses } \\
\text { Bisnis }\end{array}$ & 2.83 & 3 & Established \\
\hline MEA 3 & $\begin{array}{l}\text { Monitor, Evaluasi, dan } \\
\text { Penilaian Kesesuaian } \\
\text { dengan Kebutuhan } \\
\text { Eksternal }\end{array}$ & 2.54 & 3 & Established \\
\hline Rata-rata & & 2.77 & 3 & Established \\
\hline
\end{tabular}



Vol 1, No 1, Desember 2019

\section{Evaluasi dan Analisis Dokumen}

Setelah hasil yang didapatkan dari penyebaran kuesioner selanjutnya dilakukan studi dokomen untuk memvalidasi hasil kursioner dengan dokumen yang ada. Analisis dokumen dilakukan dengan melihat langsung dokumen-dokumen yang terkait dengan domain proses EDM 4, APO 7, DSS 6, dan MEA 3.
Kemudian hasil tingkat kematangan yang telah diperoleh dari analisis kuesioner sebelumnya kemudian akan dibandingkan dengan dokumen yang ada sesuai dengan kategori penilaian dari ISO/IEC 15504. Dokumen yang diperoleh akan dijabarkan pada tabel di bawah ini

Tabel 4.4 Tabel Analisis Dokumen

\begin{tabular}{|c|c|c|c|c|}
\hline $\begin{array}{l}\text { Domain } \\
\text { Proses }\end{array}$ & Nama Dokumen & $\begin{array}{l}\text { Maturity } \\
\text { Saat ini }\end{array}$ & $\begin{array}{l}\text { Validasi } \\
\text { Dokumen }\end{array}$ & $\begin{array}{l}\text { Maturity } \\
\text { Diharapkan }\end{array}$ \\
\hline EDM 4 & $\begin{array}{l}\text { Memastikan Pengoptimalan } \\
\text { Sumber Daya }\end{array}$ & 3 & 2 & 5 \\
\hline APO 7 & $\begin{array}{l}\text { Mengatur Sumber Daya } \\
\text { Manusia }\end{array}$ & 3 & 3 & 5 \\
\hline DSS 6 & $\begin{array}{l}\text { Mengelola dan } \\
\text { Mengkontrol Proses Bisnis }\end{array}$ & 3 & 2 & 5 \\
\hline MEA 3 & $\begin{array}{lr}\text { Monitor, } & \text { Evaluasi, dan } \\
\text { Penilaian } & \text { Kesesuaian } \\
\text { dengan } & \text { Kebutuhan } \\
\text { Eksternal } & \\
\end{array}$ & 3 & 2 & 5 \\
\hline Rata-rata & & 3 & 2.25 & 5 \\
\hline
\end{tabular}

\section{Analisis Tingkat Kesenjangan}

Berdasarkan hasil yang didapat dari hasil perhitungan kuesioner dan studi dokumen. Maka peneliti akan melakukan analisis kesenjangan dengan membandingkan tingkat kematangan saat ini dan tingkat kematangan yang di harapkan agar mendapatkan jarak (gap). Berikut adalah tabel analisis kesenjangan :

Tabel 4.4 Tabel Analisis Kesenjangan

\begin{tabular}{llll}
\hline \multirow{2}{*}{$\begin{array}{l}\text { Domain } \\
\text { Proses }\end{array}$} & Saat Ini & Diharapkan & $\begin{array}{l}\text { GAP }=(\text { diharapkan } \\
\text { - saat ini) }\end{array}$ \\
\cline { 2 - 4 } & & 5 & $5-2.78=2.22$ \\
EDM 4 & 2.75 & 5 & $5-2.94=2.06$ \\
APO 7 & 3.00 & 5 & $5-2.83=2.17$ \\
DSS 6 & 2.86 & 5 & $5-2.54=2.46$ \\
MEA 3 & 2.69 & 5 & $\mathbf{2 . 2 3}$ \\
\hline Rata-rata & & &
\end{tabular}


Dengan demikian kondisi dari

semua domain dapat digambarkan

dengan diagram berikut :

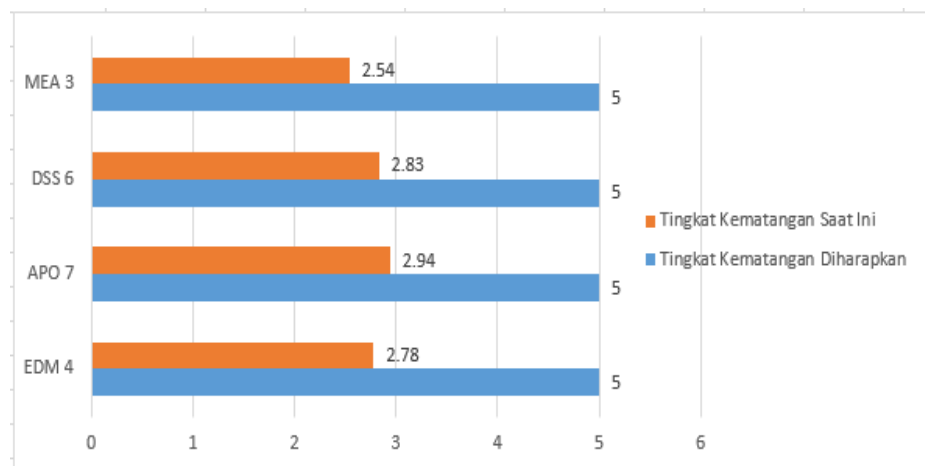

\section{Gambar 2.1 Perbandingan tingkat kematangan sistem tatakelola RS Ganeshsaat ini dengan yang diharapkan}

\section{Temuan dan Rekomendasi Perbaikan}

Dari hasil evaluasi dan analisis yang telah dilakukan pada 4 domain COBIT 5, belum ada yang mencapai level/tingkat yang diharapkan oleh RS Ganesh yaitu 5 (optimized). Hasil tersebut membuktikan bahwa masih adanya tingkat kesenjangan yang harus dibenahi dengan cara memberikan rekomendasi perbaikan agar semua domain mencapai tingkat kematangan yang diharapkan. Berikut ini merupakan rekomendasi yang harus dilaksanakan agar semua domain dapat mencapai tingkat kematangan yang diharapkan.
1. EDM
4 ,
Memastikan

Pengoptimalan Sumber Daya dan APO 7, Mengatur Sumber Daya Manusia.

1. Rekomendasi jangka pendek (2019-2021)

Melakukan pelatihan tentang cara pengoperasian sistem informasi yang di gunakan di RS Ganesha kepada staff terkait agar tidak terjadi kesalahan dalam melakukan adminstrasi sehingga dalam pelayanannya dapat melayani pasien dengan baik dan nyaman.

2. Rekomendasi jangka panjang (2019-2023)

Pada pelayanan di RS Ganesha sebaiknya di update dengan sistem baru seperti misalnya sms gateway. Sms gateway ini digunakan untuk memesan nomer pendaftaran pasien, memilih jenis layanan seperti umum atau menggunakan layanan asuransi. Pasien juga dapat melihat informasi pembayaran, melakukan registrasi kelengkapan data diri dan menyertakan keluhan yang dirasakan.Hal ini diharapkan dapat mengurangi resiko kesalahan input data pada pasien dan dapat mengurangi antrean pada saat registrasi data pasien di RS Ganesha. Jadi pasien akan dengan mudah dalam mengakses informasi tentang rumah sakit ataupun melakukan registrasi pendaftaran.

2. DSS 6, Mengelola dan Mengontrol Proses Bisnis. Rekomendasi perbaikan yang 


$$
\begin{aligned}
& \text { dapat dilakukan untuk } \\
& \text { mengatasi masalah pada } \\
& \text { domain APO } 6 \text { adalah sebagai } \\
& \text { berikut. } \\
& \text { 1. Rekomendasi jangka } \\
& \text { pendek (2019-2021) } \\
& \text { a. Dibuatkan sistem agar } \\
& \text { BPJS dapat mengakses } \\
& \text { data pasien atau pihak } \\
& \text { rumah sakit dapat } \\
& \text { mengakses data } \\
& \text { anggaran yang dimiliki } \\
& \text { oleh setiap pasien yang } \\
& \text { menggunakan BPJS. }
\end{aligned}
$$

2. Rekomendasi jangka panjang (2019-2023)

a. Membuatkan kartu khusus yang dapat menyimpan data pasien, dimana dari kartu ini akan tertera data diri pasien, tanggungan yang diberikan oleh pihak BPJS, serta nominal pertanggungan, agar kedepannya pihak RS dapat memberikan pelayanan sesuai dengan anggaran yang diberikan oleh pihak BPJS kepada pasien. Jadi dengan ini dapat memudahkan pihak rumah sakit untuk mengetahui atau memvalidasi informasi pasien serta anggaran BPJS yang dimiliki oleh pasien tersebut.

5. MEA 3, Monitor, Evaluasi, dan Penilaian Kesesuaian Dengan Kebutuhan Eksternal.

Rekomendasi perbaikan yang dapat dilakukan untuk mengatasi masalah pada MEA 3 adalah sebagai berikut.
1. Rekomendasi jangka pendek (2019-2021)

a. Penambahan loket pada apotik di rumah sakit. Sehingga dapat melayani pasien dengan lebih cepat.

2. Rekomendasi jangka panjang (2019-2023)

Pembuatan sistem pemesanan obat untuk dokter. Jadi pada saat pasien ingin mengambil obat, obat akan langsung disediakan oleh apoteker sehingga pada pasien tidak perlu menunggu lama untuk pengambilan obat di apotik.

\section{SIMPULAN DAN SARAN \\ Simpulan}

Berdasarkan analisis tentang Evaluasi Tata Kelola Dan Audit Sistem Informasi Rumah Sakit Ganesha Dengan Menggunakan Kerangka Kerja Cobit 5, maka dapat diambil kesimpulan sebagai berikut :

1. Pelaksanaan tata kelola teknologi informasi pada sistem informasi di RS Ganesha menggunakan COBIT 5 pada domain EDM 4, APO 7, DSS 6, dan MEA 3.

2. Tingkat kematangan tata kelola teknologi informasi pada sistem SIMRS Ganesha di RS Ganesha adalah 2.23 berada pada level 3 yang berarti pengelolaan teknologi informasi dilakukan secara Established.

\section{Saran}

Untuk meningkatkan tingkat kematangan dari level 3 ke level 5 sesuai yang diharapkan maka rekomendasi sebagai berikut :

a. RS Ganesha diharapkan memberi sedikit prioritas untuk anggaran dan biaya pada investasi TI agar dapat meningkatkan kualitas asset TI. 
b. Mengatasi dengan segera agar setiap bagian menggunakan computer dan sistem operasi yang sama.

c. Dibuatkan sistem agar BPJS dapat mengakses data pasien atau pihak rumah sakit dapat mengakses data anggaran yang dimiliki oleh setiap pasien yang menggunakan BPJS.

d. Membuatkan kartu khusus yang dapat menyimpan data pasien. Jadi dengan ini dapat memudahkan pihak rumah sakit untuk mengetahui atau memvalidasi informasi pasien serta anggaran BPJS yang dimiliki oleh pasien tersebut.

e. Melakukan pelatihan tentang cara pengoperasian sistem informasi di RS Ganesha kepada staff terkait agar tidak terjadi kesalahan dalam melakukan adminstrasi sehingga dalam pelayanannya dapat melayani pasien dengan baik dan nyaman.

f. Menambahkan perangkat komputer yang bisa diakses oleh pasien. Jadi pasien akan dengan mudah dalam mengakses informasi tentang rumah sakit ataupun melakukan pencarian kamar kosong yang tersedia.

g. Penambahan loket pada apotik di rumah sakit. Sehingga dapat melayani pasien dengan lebih cepat.

h. Penambahan kamar VIP sehingga dapat meningkatkan kualitas pelayanan RS Ganesha. Jadi pasien yang ingin mencari kamar VIP akan dengan mudah mendapatkannya.

i. Pembuatan sistem pemesanan obat oleh dokter. Jadi pada saat pasien ingin mengambil obat, obat akan langsung disediakan oleh apoteker sehingga pada pasien tidak perlu
menunggu
lama
untuk
pengambilan obat di apotik.
j. Menambahkan perangkat komputer yang bisa diakses oleh pasien untuk melakukan pencarian kamar kosong serta pemesanan kamar. Jadi pasien akan dengan mudah dan cepat dalam mencari kamar yang tersedia.

\section{DAFTAR PUSTAKA}

Adityawarman, 2012. Pengukuran Tingkat Kematangan

Penyelarasan Strategi

Teknologi Informasi Terhadap

Strategi Bisnis Analisis

Menggunakan Framework

Cobit 4.1 (Studi Kasus PT.

$B R I, T b k)$, Tesis, Undip.

Iskandar, 2008. Metodologi Penelitian

Pendidikan dan Sosial

(Kualitatif dan Kuantitatif),

Jakarta: GP Press.

ISACA, 2017. Control Objective for Information and Related Technology, 2017. Retrieved Juni, from ISACA: http://www.isaca.org/COBIT/ Pages/default.aspx.

ISACA, 2012. COBIT 5: Enabling Processes Governance and Management Practices, United States of America: ISACA \& ITGI.

I.G.L.A. Raditya, B.L. Sinaga, I. Wisnubhadra, 2015. "Evaluasi Tata kelola Sistem Informasi Akademik Berbasis COBIT 5 di Universitas Pendidikan Ganesha," Jurnal Buana Informatika, Vol. 6, No. 4: 279288. 
Journal of Applied Management and Accounting Science (JAMAS)

(Dewa Gede Eka Krisna Prandana, A.A. Istri Ita Paramitha, I Gede Juliana Eka Putra, 65 - 75) Vol 1, No 1, Desember 2019

Sugiono, 2013. Memahami Penelitian Kualitatif. Bandung: Alfabeta.

A. Swastika, I.G.L.A Raditya, 2016.

Audit Sistem Informasi dan

Tata Kelola Teknologi

Informasi: Implementasi dan

Studi Kasus, Yogyakarta: Andi. 